\title{
Perioperative Blood Pressure Control in Carotid Artery Stenosis Patients With Carotid Angioplasty Stenting: A Retrospective Analysis of 173 Cases
}

\author{
Longlong Zheng ${ }^{\dagger}$, Jiang $\mathrm{Li}^{\dagger}$, Haixiao Liu ${ }^{\dagger}$, Hao Guo, Lei Zhao, Hao Bai, Zhongjun Yan and \\ Yan $Q u^{*}$ \\ Department of Neurosurgery, Tangdu Hospital, The Fourth Military Medical University, Xi'an, China
}

OPEN ACCESS

Edited by: Xin Cheng,

Fudan University, China

Reviewed by:

Yuishin Izumi,

Tokushima University, Japan

Maurice Giroud,

Centre Hospitalier Regiona

Universitaire De Dijon, France

*Correspondence:

Yan Qu

yanqu0123@fmmu.edu.cn

tThese authors have contributed equally to this study

Specialty section:

This article was submitted to

Stroke,

a section of the journal

Frontiers in Neurology

Received: 30 May 2020 Accepted: 30 September 2020

Published: 30 October 2020

Citation:

Zheng L, Li J, Liu H, Guo H, Zhao L,

Bai H, Yan Z and Qu Y (2020)

Perioperative Blood Pressure Control

in Carotid Artery Stenosis Patients

With Carotid Angioplasty Stenting: A

Retrospective Analysis of 173 Cases.

Front. Neurol. 11:567623.

doi: 10.3389/fneur.2020.567623
Background: Carotid angioplasty stenting (CAS) is a currently widely used surgical treatment of carotid artery stenosis. However, the influences of the perioperative blood pressure (BP) on patients' prognosis remain unclear.

Objective: The present study was designed to explore the effects of different perioperative BP control strategies on CAS patients' prognosis.

Methods: One hundred seventy-three consecutive patients admitted between January 2016 and April 2019 were reviewed retrospectively. The outcomes of patients with different systolic $\operatorname{BP}(<120,120-130$, and $>130 \mathrm{mmHg})$ before CAS and within $24 \mathrm{~h}$ after CAS were compared. The primary outcomes were the incidence of secondary cerebral infarction $(\mathrm{Cl})$ and intracranial hemorrhage $(\mathrm{ICH})$ after CAS. The secondary outcome was the incidence of unfavorable discharge and in-hospital death. The unfavorable discharge was defined as modified Rankin Scale (mRS) score 3-5 at discharge.

Results: There was no significant difference between the incidences of $\mathrm{ICH}(P=0.803)$ and $\mathrm{Cl}(P=0.410)$ in patients with different BP before CAS. The patients with post-CAS BP values of $>130 \mathrm{mmHg}$ had a 37.67-fold increased risk (95\% Cl: 6.79-209.01) of ICH compared with others, while no significant difference was observed on the incidence of $\mathrm{Cl}(P=0.174)$ among patients with different post-CAS BP values. The patients with post-CAS BP values of $>130 \mathrm{mmHg}$ also had a significantly higher incidence of unfavorable discharge $(P=0.002)$ and in-hospital death $(P=0.001)$ compared with others.

Conclusion: High BP (>130 $\mathrm{mmHg}$ ) within $24 \mathrm{~h}$ after CAS significantly increases the risks of secondary cerebral hemorrhage, unfavorable discharge, and in-hospital death. Thus, the BP should be controlled below $130 \mathrm{mmHg}$ in the first $24 \mathrm{~h}$ after CAS.

Keywords: cerebral infarction, intracranial hemorrhage, carotid angioplasty stenting, carotid artery stenosis, blood pressure control 


\section{INTRODUCTION}

Stroke has become the leading cause of death worldwide (1-3). Even worse, the absolute numbers of strokes will continue to increase worldwide for a long time along with the increasing of the aging population and the high prevalence of smoking and hypertension $(4,5)$, and most importantly due to the increasing incidence of stroke in younger persons aged $<65$ years $(6,7)$. In addition, the proportion of ischemic strokes is increasing in many developing countries such as China $(4,8)$. Currently, about $85 \%$ of strokes are cerebral ischemia, which is characterized by a sudden loss of neurological function due to insufficient blood supply to the brain (9).

Carotid artery stenosis is a well-documented risk factor for cerebrovascular diseases such as acute ischemic stroke or transient ischemic attack (10). It is reported that atherosclerotic disease of the extracranial internal carotid artery is responsible for $20-25 \%$ of ischemic strokes (11). The evidence of the optimal treatment strategies for different patients is still insufficient (10, 12). For asymptomatic carotid artery stenosis patients with stenosis $<70 \%$, medical therapy and control of risk factors are the currently recommended treatment strategies. However, for symptomatic patients with stenosis of more than $50 \%$ or asymptomatic patients with stenosis of more than $70 \%$, surgical treatment could be considered (13-15).

Current surgical treatments for carotid stenosis include carotid endarterectomy (CEA) and carotid angioplasty stenting (CAS) (16). Although CEA has been established as the gold standard treatment for symptomatic severe carotid stenosis, CAS, as a less-invasive procedure, has been performed as an alternative to CEA $(17,18)$. Breakthroughs have been made since the treatment of endovascular recanalization for the symptomatic internal carotid artery stenosis patients in the subacute to chronic stage was first reported (19). Compared with CEA, CAS has advantages in the treatment of chronic carotid artery stenosis in some clinical situations (12, 20-23). For example, CAS patients can recover quickly and have shorter hospital stays. Besides, CAS can be performed on patients with severe stenosis of the internal carotid artery. Moreover, tandem lesions can be treated simultaneously.

Cerebral hyperperfusion syndrome (CHS), which could further lead to cerebral swelling or intracranial hemorrhage (ICH), occurs on $1.1-6.8 \%$ of intracranial arterial stenosis patients after CAS (24-26). The pathophysiology of CHS is characterized by the increase of cerebral blood flow due to the dysregulation of the cerebral vascular system and hypertension (27). Therefore, controlling post-CAS blood pressure (BP) at a low level could reduce the risk of CHS and ICH (28). However, excessive lowering of BP may aggravate the cerebral ischemia. Currently, the standard of BP control after CAS is still controversial.

Thus we conducted this retrospective study of 173 CAS patients at Tangdu Hospital from January 2016 to April 2019 to explore the effect of different perioperative $\mathrm{BP}$ control strategies on the risk of post-CAS ICH, cerebral infarction (CI), and prognosis of CAS patients.

\section{MATERIALS AND METHODS}

\section{Study Design and Population}

The present study was designed to compare the incidence rate of CI, ICH, unfavorable discharge [modified Rankin Scale (mRS) 3 5], and in-hospital death in carotid artery stenosis patients with different perioperative BP after CAS. This study was approved by the Biological and Medical Ethics Committee of Tangdu Hospital (No. TDLL-20181205) and performed in Tangdu Hospital strictly following the Declaration of Helsinki (29). The medical records of all patients who underwent CAS at Tangdu Hospital between January 2016 and April 2019 were retrospectively reviewed.

Then, the participants were selected according to the following criteria.

\section{Inclusion Criteria}

1. $18-80$ years old.

2. Symptomatic patients with stenosis more than $50 \%$ or asymptomatic patients with stenosis more than $70 \%$ (demonstrated by digital subtraction angiography).

3. Without newly emerging ischemic stroke within 2 weeks.

4. Underwent CAS during the hospitalization.

\section{Exclusion Criteria}

1. Definite contraindications against BP control (such as renal failure and hypovolemic shock).

2. A tendency of severe bleeding (such as a peptic ulcer or gastrointestinal bleeding).

3. A history of CEA or occlusion after stenting.

4. A history of ICH within 30 days.

5. Concurrent serious severe heart or lung dysfunction.

\section{Treatment}

All patients obtained standard treatment in accordance with the recommendations of the American Heart Association/American Stroke Association (AHA/ASA). Medical histories were recorded after admission in a timely manner. Neurological status was documented on admission using the National Institutes of Health Stroke Scale (NIHSS) by certified neurologists. Routine radiological examination and blood tests were performed during the perioperative period. The strategies of BP control were specified based on the physician's judgment of the clinical status of patients.

\section{Surgical Procedures}

All of the surgeries were performed by a well-trained vascular surgery team with more than 10 years of experience. All patients received antiplatelet medication (aspirin $100 \mathrm{mg} /$ day and clopidogrel $75 \mathrm{mg} /$ day) for at least 5 days before the surgery, which were performed under local anesthesia. A dose of 3,000 IU heparin was given by intravenous bolus injection intraoperatively to each patient. Cerebral angiography was performed before CAS to measure the stenosis degree according to the North American Symptomatic Carotid Endarterectomy Trial (NASCET) criteria. A protective distal filter device (EV3) was carefully deployed in the normal vessel distal to the stenosis. A balloon with a diameter of 4-6 $\mathrm{mm}$ was performed for pre- or post-dilation if needed. Then, a self-expanding stent was deployed over the lesion. 
Computed tomography (CT) or magnetic resonance imaging (MRI) was performed both before and after the surgery to assess $\mathrm{ICH}$ and $\mathrm{CI}$.

\section{Data Collection and Outcomes Evaluation}

General characteristics (such as sex, age, etc.) were collected from the patient information management department of our hospital. Past medical history (smoking, alcohol, hypertension, coronary artery disease, hyperlipidemia, and diabetes), degree of stenosis, and contralateral lesions were obtained from medical documentation and cerebral angiography report in our hospital. The preoperative severity of disease was evaluated by the preoperative NIHSS score, which was also collected from medical documentation. The baseline BP values were obtained as the mean values of three random systolic BP (SBP) in the last $24 \mathrm{~h}$ before CAS, and the post-CAS BP levels were acquired as the mean values of every hourly SBP in the first $24 \mathrm{~h}$ after CAS. If ICH or CI occurs within $24 \mathrm{~h}$ post-CAS, the subsequent BP values would be excluded from the analysis. All the BP records were collected from medical documentation. The outcomes of patients with different systolic BP $(<120 \mathrm{mmHg}, 120-130$ $\mathrm{mmHg}$, and $>130 \mathrm{mmHg}$ ) before CAS and within $24 \mathrm{~h}$ after CAS were compared.
The primary outcomes were the incidence rate of $\mathrm{ICH}$ and CI after CAS during the hospitalization, which were assessed by CT or MRI scan. ICH was defined as punctate or confluent hyper-densities consistent with blood within the parenchyma of the cerebral hemispheres or within the subarachnoid space as demonstrated on CT imaging (30). CI was defined as episode of neurological dysfunction caused by focal cerebral based on CT or MRI (31). Spotty CI was ruled out, and carotid ultrasound was performed post procedure to assess thrombosis or occlusion of the carotid artery. All assessments were finished separately by two investigators after carefully comparing the cerebral imaging before and after CAS. The secondary outcomes were in-hospital death and unfavorable discharge, which was defined as mRS score 3-5 at discharge.

\section{Statistical Analysis}

Statistical calculations were performed using SPSS version 23.0 (IBM, Armonk, USA). The chi-squared tests and Fisher's exact tests were used to analyze the comparison of categorical data, which were displayed as percentages. Wilcoxon signed-rank tests were used to analyze the comparison of continuous data, which were presented as median scores with interquartile ranges because of non-normal data distributions. Multivariate logistic regression analysis was used to detect the risk factors of $\mathrm{ICH}$,

TABLE 1 | General characteristics in each group.

\begin{tabular}{|c|c|c|c|c|c|}
\hline Characteristics & Total & $<120 \mathrm{mmHg}$ & $120-130 \mathrm{mmHg}$ & $>130 \mathrm{mmHg}$ & $P$-value \\
\hline Gender (female) & $33 / 173$ & $17.4 \%(20 / 115)$ & $15.0 \%(6 / 40)$ & $38.9 \%(7 / 18)$ & 0.097 \\
\hline Age (years) & & $62.9 \pm 8.7$ & $63.2 \pm 9.0$ & $65.2 \pm 11.1$ & 0.749 \\
\hline Grade of hypertension & & $2(0-3)$ & $3(2-3)$ & $2.5(2-3)$ & 0.154 \\
\hline Diabetes mellitus & & $20.0 \%(23 / 115)$ & $17.5 \%(7 / 40)$ & $38.9 \%(7 / 18)$ & 0.179 \\
\hline Coronary artery disease & & $13.0 \%(15 / 115)$ & $12.5 \%(5 / 40)$ & $11.1 \%(2 / 18)$ & 1 \\
\hline Hyperlipidemia & & $27.0 \%(31 / 115)$ & $32.5 \%(13 / 40)$ & $38.9 \%(7 / 18)$ & 0.502 \\
\hline Alcoholic & & $22.6 \%(26 / 115)$ & $25.0 \%(10 / 40)$ & $22.2 \%(4 / 18)$ & 0.96 \\
\hline Smoking & & $48.7 \%(56 / 115)$ & $45.0 \%(18 / 40)$ & $33.3 \%(6 / 18)$ & 0.501 \\
\hline Bilat lesions & & $9.6 \%(11 / 115)$ & $17.5 \%(7 / 40)$ & $22.2 \%(4 / 18)$ & 0.159 \\
\hline Stenosis (NASCET, \%) & & $79.1 \pm 8.1 \%$ & $81.4 \pm 7.9 \%$ & $85.4 \pm 8.8 \%$ & 0.006 \\
\hline Preoperative NIHSS score & & $0(0-0)$ & $0(0-1)$ & $0(0-2.25)$ & 0.426 \\
\hline Postoperative MRI & & $47.0 \%(54 / 115)$ & $55.0 \%(22 / 40)$ & $27.8 \%(5 / 18)$ & 0.161 \\
\hline Spotty infarction & & $79.6 \%(43 / 54)$ & $72.9 \%(16 / 22)$ & $40.0 \%(2 / 5)$ & 0.129 \\
\hline
\end{tabular}

NIHSS, National Institutes of Health Stroke Scale; MRI, Magnetic Resonance Imaging; NASCET, North American Symptomatic Carotid Endarterectomy Trial.

TABLE 2 | The incidence of post-CAS CI, ICH, unfavorable discharge, and in-hospital death in the patients with different baseline BP and post-CAS BP.

\begin{tabular}{|c|c|c|c|c|c|}
\hline & & $<120 \mathrm{mmHg}$ & $120-130 \mathrm{mmHg}$ & $>130 \mathrm{mmHg}$ & $P$-value \\
\hline \multirow[t]{2}{*}{ Baseline BP } & $\mathrm{Cl}$ & $0 \%(0 / 24)$ & $7.9 \%(6 / 76)$ & $4.1 \%(3 / 73)$ & 0.410 \\
\hline & $\mathrm{ICH}$ & $4.2 \%(1 / 24)$ & $7.9 \%(6 / 76)$ & $9.6 \%(7 / 73)$ & 0.803 \\
\hline \multirow[t]{4}{*}{24 h BP } & $\mathrm{Cl}$ & $3.5 \%(4 / 115)$ & $7.5 \%(3 / 40)$ & $11.1 \%(2 / 18)$ & 0.174 \\
\hline & $\mathrm{ICH}$ & $2.6 \%(3 / 115)$ & $5.0 \%(2 / 40)$ & $50 \%(9 / 18)$ & $<0.0001$ \\
\hline & Unfavorable discharge & $1.7 \%(2 / 115)$ & $0 \%(0 / 40)$ & $22.2 \%(4 / 18)$ & 0.002 \\
\hline & In-hospital death & $0 \%(0 / 115)$ & $0 \%(0 / 40)$ & $16.7 \%(3 / 18)$ & 0.001 \\
\hline
\end{tabular}

Cl, Cerebral Infarction; ICH, Intracranial Hemorrhage. 
CI, unfavorable discharge, and in-hospital death. Statistical test results were recognized as significant when the $P$-value was $<0.05$.

\section{RESULTS}

\section{Patient Numbers}

Two hundred eighty-eight consecutive patients with carotid artery stenosis who underwent CAS admitted to our hospital between January 2016 and April 2019 were retrospectively reviewed. Among them, 115 patients were excluded due to the lack of clinical or cerebral imaging data; then, a total of 173 patients met the inclusion criteria and were enrolled in this study.

\section{General Characteristics}

Among the 173 included patients, 140 were male and 33 were female. The age of the patients ranged from 39 to 81 , and the average age was $63.2 \pm 9.0$. The average degree of stenosis was $80.3 \pm 8.3 \%$. Among the 115 excluded patients, 97 were male and 18 were female. The age of the patients ranged from 42 to 80 , and the average age was $63.7 \pm 7.7$. The average degree of stenosis was $78.5 \pm 8.5 \%$. There was no significant difference in the demographic and baseline characteristics among the BP groups divided according to the post-CAS systolic BP levels (Table 1).

\section{OUTCOME ASSESSMENT}

After CAS, 14 (8.1\%) patients suffered different types of ICH, which included 1 subarachnoid hemorrhage, 1 contralateral intracerebral microhemorrhage, 1 bilateral subdural hemorrhage, 1 posterior cerebral circulation hemorrhage, 6 intracerebral microhemorrhages, and 4 intracerebral hemorrhages. Nine (5.2\%) patients suffered CI. Three (1.73\%) patients died before discharge. Besides, unfavorable discharge occurred in six (3.47\%) cases (Table 2). Among the 115 excluded patients, the incidence of ICH or CI cannot be identified due to the lack of clinical or cerebral imaging data. No one died or suffered unfavorable discharge.

Among the three BP groups divided according to the baseline $\mathrm{BP}$ levels, there were no significant differences in the incidence of both $\mathrm{CI}(P=0.410)$ and ICH $(P=0.803)$. However, among the three $\mathrm{BP}$ groups divided according to the post-CAS BP levels, there were significant differences on the incidence of $\mathrm{ICH}$ $(P<0.0001)$, unfavorable discharge $(P=0.002)$, and in-hospital death $(P=0.001)$, whereas there was no significant difference on the incidence of CI $(P=0.174)$ (Table 2).

Within different postoperative BP groups, the $>130 \mathrm{mmHg}$ group had a significantly higher incidence of ICH $(P<0.0001$ vs. the $<120 \mathrm{mmHg}$ group, $P<0.0001$ vs. the $120-130 \mathrm{mmHg}$ group), unfavorable discharge ( $P=0.003$ vs. the $<120 \mathrm{mmHg}$ group, $P=0.007$ vs. the $120-130 \mathrm{mmHg}$ group), and in-hospital death $(P=0.002$ vs. the $<120 \mathrm{mmHg}$ group, $P=0.026$ vs. the $120-130 \mathrm{mmHg}$ group) than that in the other two groups. However, there was no significant difference on the incidence of ICH $(P=0.604)$ and unfavorable discharge $(P=1)$ between the $<120 \mathrm{mmHg}$ group and the $120-130 \mathrm{mmHg}$ group (Table 3 ).
TABLE 3 | The difference in the incidence of post-CAS, ICH, unfavorable discharge, and in-hospital death between different post-CAS BP groups.

\begin{tabular}{lccc}
\hline$P$-value & $\begin{array}{c}<\mathbf{1 2 0} \mathbf{~ m m H g} \\
\text { vs. 120-130 } \\
\mathbf{m m H g}\end{array}$ & $\begin{array}{c}<\mathbf{1 2 0} \mathbf{~ m m H g} \text { vs. } \\
>\mathbf{1 3 0} \mathbf{~ m m H g}\end{array}$ & $\begin{array}{c}\mathbf{1 2 0} \mathbf{~ m m}-\mathbf{1 3 0} \mathbf{~ m m ~ H g} \\
\text { vs. }>\mathbf{1 3 0 ~} \mathbf{m m g}\end{array}$ \\
\hline $\mathrm{ICH}$ & 0.604 & $<0.0001$ & $<0.0001$ \\
Unfavorable discharge & 1 & 0.003 & 0.007 \\
In-hospital death & $\mathrm{NA}$ & 0.002 & 0.026 \\
\hline
\end{tabular}

ICH, Intracranial Hemorrhage; NA, Not Applicable.

TABLE 4 | Multivariate logistic regression of potential influentially factors on the post-CAS ICH.

\begin{tabular}{|c|c|c|c|}
\hline & & OR $(95 \% \mathrm{Cl})$ & $P$-value \\
\hline $\begin{array}{l}24 \mathrm{~h} \mathrm{BP} \\
\text { (Reference is } \leq 130 \mathrm{mmHg} \text { ) }\end{array}$ & $>130 \mathrm{mmHg}$ & 37.67 (6.79-209.01) & $<0.0001$ \\
\hline Baseline BP & & 0.977 (0.91-1.05) & 0.516 \\
\hline Age & & $0.938(0.86-1.02)$ & 0.130 \\
\hline Grade of hypertension & & $1.12(0.59-2.12)$ & 0.740 \\
\hline $\begin{array}{l}\text { Bilat lesions } \\
\text { (Reference is No) }\end{array}$ & Yes & 1.67 (0.30-9.29) & 0.560 \\
\hline Stenosis (NASCET) & & 1.194 (1.063-1.342) & 0.003 \\
\hline Preoperative NIHSS score & & $0.54(0.18-1.66)$ & 0.282 \\
\hline
\end{tabular}

NIHSS, The National Institutes of Health Stroke Scale; NASCET, North American Symptomatic Carotid Endarterectomy Trial.

TABLE 5 | Logistic regression of risk factors of unfavorable discharge and in-hospital death.

\begin{tabular}{|c|c|c|c|c|}
\hline & \multicolumn{2}{|c|}{ Unfavorable discharge } & \multicolumn{2}{|c|}{ In-hospital death } \\
\hline & OR (95\% Cl) & $P$-value & OR (95\% Cl) & $P$-value \\
\hline \multicolumn{5}{|c|}{ Hemorrhage } \\
\hline NO & 1.00 & & 1.00 & \\
\hline YES & $31.40(5.13-192.59)$ & $<0.0001$ & $26.33(2.23-311.69)$ & 0.009 \\
\hline \multicolumn{5}{|c|}{ Infarction } \\
\hline NO & 1.00 & & 1.00 & \\
\hline YES & $11.43(1.78-73.30)$ & 0.01 & $10.13(0.83-123.75)$ & 0.07 \\
\hline
\end{tabular}

After adjusting for confounding variables including age, baseline BP, the grade of hypertension, bilat lesions, degree of stenosis (NASCET), and preoperative NIHSS score, multivariate logistic regression analysis showed that the patients with postCAS BP of $>130 \mathrm{mmHg}$ had a 37.67 -fold increased risk $(95 \%$ CI: 6.79-209.01) of post-CAS ICH compared with those with post-CAS BP of $\leq 130 \mathrm{mmHg}$ (Table 4).

Furthermore, the patients with post-CAS ICH had a 31.40fold increased risk (95\% CI: 5.13-192.59) of unfavorable discharge and a 26.33-fold increased risk (95\% CI: 2.23-311.69) of in-hospital death, compared with others. Meanwhile, the patients with post-CAS CI had an 11.43-fold increased risk (95\% CI: 1.78-73.30) of unfavorable discharge and a tendency of an increase of the risk (OR: 10.13, 95\% CI: $0.83-123.75$ ) of in-hospital death, compared with others (Table 5).

Typical cases of post-CAS ICH and CI are shown in Figure 1. Case \# 1 was a patient with a $99 \%$ stenosis in the proximal segment 
A
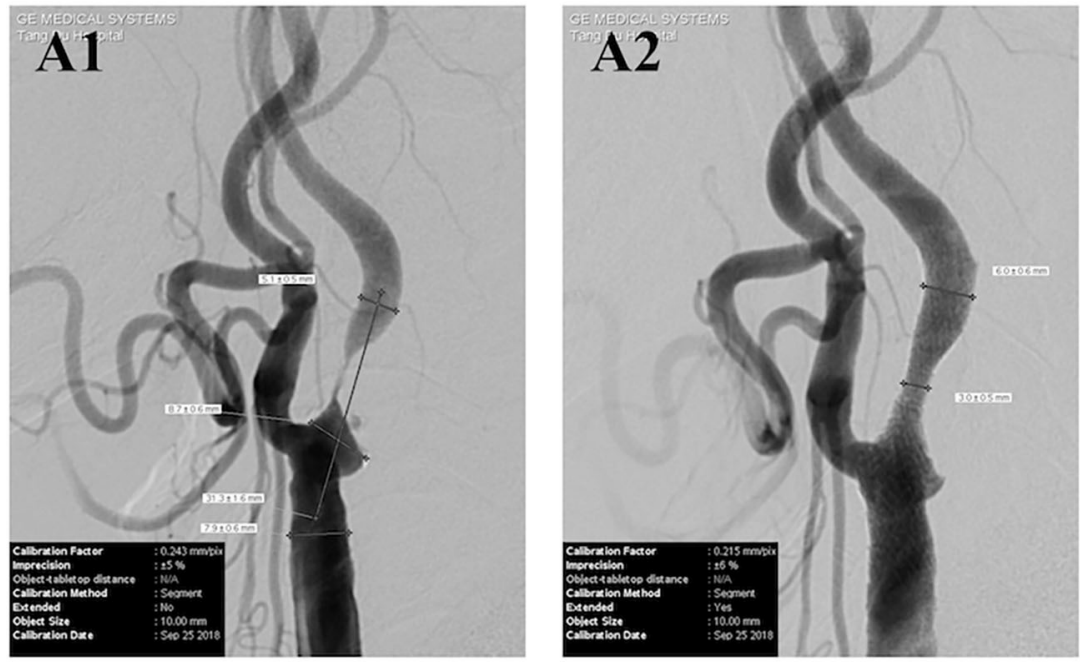

B
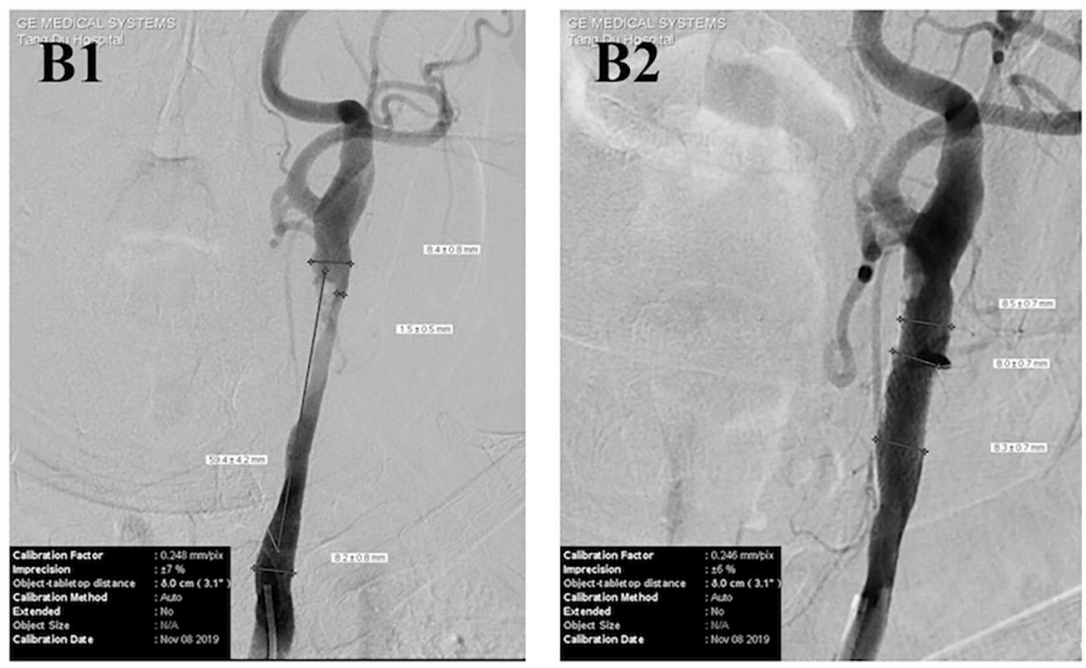

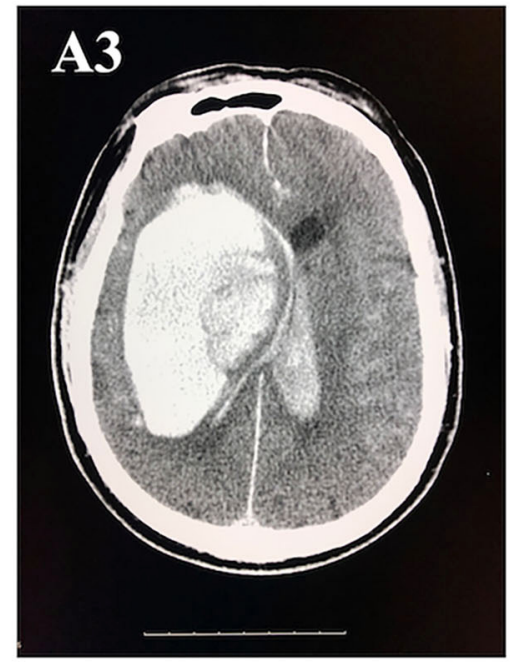

FIGURE 1 | Typical cases of post-CAS ICH and Cl. (A) Case \#1 (A1) DSA showed a 99\% stenosis in the proximal segment of the right internal carotid artery. (A2) DSA showed a 50\% residual stenosis in the proximal segment of the right internal carotid artery after CAS. (A3) CT performed $25 \mathrm{~h}$ after CAS showed a huge right intracerebral hematoma. (B) Case \#2 (B1) DSA showed an 82\% stenosis in the left carotid artery. (B2) DSA showed a nearly 0\% residual stenosis in the left carotid artery after CAS. (B3) CT scan performed $58 \mathrm{~h}$ after CAS showed a left massive $\mathrm{Cl}$.

of the right internal carotid artery. The baseline BP, immediate post-CAS BP, and average BP within $24 \mathrm{~h}$ after CAS were $125 / 75,123 / 83$, and $156 / 82 \mathrm{mmHg}$, respectively. This patient had symptoms of headache, nausea, and vomiting after CAS. The CT scan performed $25 \mathrm{~h}$ after CAS showed a huge right intracerebral hematoma (Figure 1A3), which was considered to be caused by poor post-CAS BP control and CHS. This patient eventually died in the hospital. Case \#2 was a patient with an $82 \%$ stenosis in the left carotid artery. The baseline BP, immediate post-CAS BP, and average BP within $24 \mathrm{~h}$ after CAS were 125/61, 115/74, and $101 / 61 \mathrm{mmHg}$, respectively. The CT scan performed $58 \mathrm{~h}$ after CAS showed a massive left CI (Figure 1B3). Carotid ultrasound post-procedure excluded thrombosis or occlusion of the carotid artery. This patient eventually suffered unfavorable discharge.

\section{DISCUSSION}

The present study was designed to explore the effects of different perioperative BP control strategies on CAS patients' prognosis. We found that the post-CAS BP was significantly correlated with $\mathrm{ICH}$, unfavorable discharge, and in-hospital death, while there was no significant association with CI in CAS patients, although baseline BP did not appear to have an effect on the incidence of 
both $\mathrm{CI}$ and ICH. The patients with post-CAS BP values of $>130$ $\mathrm{mmHg}$ had a 37.67-fold increased risk of ICH compared with others, and patients who suffered ICH had a 31.40-fold increased risk of unfavorable discharge and 26.33-fold increased risk of inhospital death. These results suggest that the systolic pressure within $24 \mathrm{~h}$ after CAS should be controlled below $130 \mathrm{mmHg}$ to avoid post-CAS ICH.

CAS has been demonstrated to be valuable in the treatment of chronic carotid artery stenosis. Post-CAS ICH is characterized with early occurrence, high disability, and mortality. As the most common cause, the mechanisms of post-CAS CHS might include: (1) the failure of vessels' autoregulatory mechanisms during the sudden increase of cerebral blood flow after revascularization in long-standing hypoperfused tissues, (2) the disturbance of baroreflex secondary to revascularization, and (3) the disturbance of the trigeminovascular system (32). Thus, maintaining hemodynamic stability may be an important way to prevent post-CAS CHS and $\mathrm{ICH}$. However, most of the previous literature about $\mathrm{CHS}$ and $\mathrm{ICH}$ was concentrated on the difference of post-surgery ICH incidence between CAS and CEA $(30,33-35)$. Some other studies were focused on the predictive risk factors of CHS and ICH after CAS (36-38). Besides, as ischemic post-CAS stroke, the mechanisms of CI can be classified as (1) carotid-embolic, (2) hemodynamic, (3) thrombosis or occlusion of the carotid artery, (4) hyperperfusion, (5) cardioembolic, (6) multiple, or (7) undetermined (39). A previous study showed that hemodynamic disturbance was an important mechanism, and careful attention to BP control could lower the incidence of ischemic post-CAS stroke (31). There is still limited clinical evidence on how to prevent ICH and CI after CAS, which is one of the primary issues in the management of patients and can directly improve the patient's prognosis.

In 1999, a literature first reported ICH after CAS and pointed out that attention should be paid to perioperative BP (40). In 2017, A meta-analysis showed that periprocedural hypertension was the most common risk factor of CHS and ICH (32). Another literature (39) proved that careful attention to BP control could lower the incidence of procedural stroke. In addition, previous studies have reached a common conclusion that post-CAS BP should be controlled below a certain level (41-44). However, it is still unclear whether lower BPs increase the risk of post-CAS CI. Although the present study showed that difference between the incidence of CI in each post-surgery BP group had no statistical significance, we provided a more specific strategy of BP control after CAS than the previous studies.

This study has several limitations. At first, the incidence of post-CAS ICH in this study was $8.1 \%$, which was much higher than the incidence range of $0.36-4.5 \%$ reported in previous studies $(26,38)$. The incidence may be enlarged by two reasons. One is the selection bias inherent in a retrospective study, which

\section{REFERENCES}

1. Liu M, Wu B, Wang WZ, Lee LM, Zhang SH, Kong LZ. Stroke in China: epidemiology, prevention, and management strategies. Lancet Neurol. (2007) 6:456-64. doi: 10.1016/S1474-4422(07)70004-2 is characterized by excluding 115 patients in whom no one died or suffered unfavorable discharge in this study, despite the lack of clinical or cerebral imaging data. Another is that we have included six intracerebral microhemorrhage patients who suffered no CHS symptoms in the analysis, while most of the previous studies focused on ICH in the context of CHS. Besides, the $5.2 \%$ incidence of $\mathrm{CI}$ is similar to the $4.3 \%$ of a previous study (30). Although we have excluded spotty CI to be directly related to the operation by MRI and assessed thrombosis or occlusion of the carotid artery by carotid ultrasound post-procedure, it is difficult to identify whether post-CAS CI was caused by carotidembolic or hemodynamics. The reason we did not find significant association between post-CAS BP and CI may be the lack of essential cerebral imaging data and the small sample size of retrospective study. Last, the characteristics of a single-center study and the lack of randomization due to the retrospective design may not make the results generalizable. Thus, prospective multi-center randomized controlled clinical trials with a larger sample size and adequately pre-defined radiological examination protocol are needed.

In conclusion, the baseline systolic $\mathrm{BP}$ has no significant influence on post-CAS ICH and CI, while the BP within $24 \mathrm{~h}$ after CAS is closely related to the post-CAS ICH and patients' prognosis and should be controlled lower than $130 \mathrm{mmHg}$.

\section{DATA AVAILABILITY STATEMENT}

The original contributions presented in the study are included in the article/supplementary materials, further inquiries can be directed to the corresponding author/s.

\section{ETHICS STATEMENT}

This study was approved by the biological and medical ethics committee of Tangdu Hospital (No. TDLL-20181205).

\section{AUTHOR CONTRIBUTIONS}

All authors of this work met ICMJE criteria for authorship and made substantial contributions to the conception and design, acquisition of data, analysis and interpretation of data, drafting, critical revising, and final approval of this manuscript.

\section{FUNDING}

This work was supported by the Science and Technology Integrated Innovation Project Foundation of Shaanxi Province (grant no. 2016KTCL03-02) and the Science and Technology Innovation Development Fund of Tangdu Hospital.

2. Donnan GA, Fisher M, Macleod M, Davis SM. Stroke. Lancet. (2008) 371:1612-23. doi: 10.1016/S0140-6736(08)60694-7

3. Liu L, Wang D, Wong KS, Wang Y. Stroke and stroke care in China: huge burden, significant workload, and a national priority. Stroke. (2011) 42:3651-4. doi: 10.1161/STROKEAHA.111.635755 
4. Kinlay S. Changes in stroke epidemiology, prevention, and treatment. Circulation. (2011) 124:e494-6. doi: 10.1161/CIRCULATIONAHA.111. 069633

5. Kunst AE, Amiri M, Janssen F. The decline in stroke mortality: exploration of future trends in 7 Western European countries. Stroke. (2011) 42:2126-30. doi: 10.1161/STROKEAHA.110.599712

6. Group GBDNDC. Global, regional, and national burden of neurological disorders during 1990-2015: a systematic analysis for the Global Burden of Disease Study 2015. Lancet Neurol. (2017) 16:877-97. doi: 10.1016/S1474-4422(17)30299-5

7. Hankey GJ. Stroke. Lancet. (2017) 389:641-54. doi: 10.1016/S0140-6736(16)30962-X

8. Wang W, Jiang B, Sun H, Ru X, Sun D, Wang L, et al. Prevalence, incidence, and mortality of stroke in China: results from a nationwide population-based survey of 480687 adults. Circulation. (2017) 135:759-71. doi: 10.1161/CIRCULATIONAHA.116.025250

9. Zerna C, Thomalla G, Campbell BCV, Rha JH, Hill MD. Current practice and future directions in the diagnosis and acute treatment of ischaemic stroke. Lancet. (2018) 392:1247-56. doi: 10.1016/S0140-6736(18)31874-9

10. Barrett KM, Brott TG. Stroke caused by extracranial disease. Circ Res. (2017) 120:496-501. doi: 10.1161/CIRCRESAHA.117.310138

11. Alcalde-Lopez J, Zapata-Arriaza E, Cayuela A, Moniche F, Escudero-Martinez I, Ortega-Quintanilla J, et al. Safety of early carotid artery stenting for symptomatic stenosis in daily practice. Eur J Vasc Endovasc Surg. (2018) 56:776-82. doi: 10.1016/j.ejvs.2018.07.026

12. Levy EI, Mocco J, Samuelson RM, Ecker RD, Jahromi BS, Hopkins LN. Optimal treatment of carotid artery disease. J Am Coll Cardiol. (2008) 51:979-85. doi: 10.1016/j.jacc.2007.10.052

13. Raman G, Moorthy D, Hadar N, Dahabreh IJ, O’Donnell TF, Thaler $\mathrm{DE}$, et al. Management strategies for asymptomatic carotid stenosis: a systematic review and meta-analysis. Ann Intern Med. (2013) 158:676-85. doi: 10.7326/0003-4819-158-9-201305070-00007

14. Abbott AL, Paraskevas KI, Kakkos SK, Golledge J, Eckstein HH, DiazSandoval LJ, et al. Systematic review of guidelines for the management of asymptomatic and symptomatic carotid stenosis. Stroke. (2015) 46:3288-301. doi: 10.1161/STROKEAHA.115.003390

15. Kapila V, Jetty P, Basile VS, Dubois L. Management of transient ischemic attack or nondisabling stroke related to extracranial internal carotid artery stenosis. CMAJ. (2019) 191:E418-22. doi: 10.1503/cmaj.180735

16. Roffi M, Cremonesi A. Carotid artery stenting vs. endarterectomy for carotid stenosis. Lancet. (2010) 376:327; author reply 327-8. doi: 10.1016/S0140-6736(10)61177-4

17. Brott TG, Hobson RWII, Howard G, Roubin GS, Clark WM, Brooks $\mathrm{W}$, et al. Stenting vs. endarterectomy for treatment of carotid-artery stenosis. $N$ Engl J Med. (2010) 363:11-23. doi: 10.1056/NEJMoa09 12321

18. Gonzales NR, Demaerschalk BM, Voeks JH, Tom M, Howard G, Sheffet AJ, et al. Complication rates and center enrollment volume in the carotid revascularization endarterectomy vs. stenting trial. Stroke. (2014) 45:3320-4. doi: 10.1161/STROKEAHA.114.0 06228

19. Terada T, Okada H, Nanto M, Shintani A, Yoshimura R, Kakishita K, et al. Endovascular recanalization of the completely occluded internal carotid artery using a flow reversal system at the subacute to chronic stage. J Neurosurg. (2010) 112:563-71. doi: 10.3171/2009.6.JNS09125

20. Kao HL, Lin MS, Wang CS, Lin YH, Lin LC, Chao CL, et al. Feasibility of endovascular recanalization for symptomatic cervical internal carotid artery occlusion. J Am Coll Cardiol. (2007) 49:765-71. doi: 10.1016/j.jacc.2006.11.029

21. Lin MS, Lin LC, Li HY, Lin CH, Chao CC, Hsu CN, et al. Procedural safety and potential vascular complication of endovascular recanalization for chronic cervical internal carotid artery occlusion. Circ Cardiovasc Interv. (2008) 1:119-25. doi: 10.1161/CIRCINTERVENTIONS.108. 772350

22. Doig D, Brown MM. Carotid stenting vs. endarterectomy. Annu Rev Med. (2012) 63:259-76. doi: 10.1146/annurev-med-081210-101714

23. White CJ. Carotid artery stenting. J Am Coll Cardiol. (2014) 64:722-31. doi: 10.1016/j.jacc.2014.04.069
24. Schoser BG, Heesen C, Eckert B, Thie A. Cerebral hyperperfusion injury after percutaneous transluminal angioplasty of extracranial arteries. J Neurol. (1997) 244:101-4. doi: 10.1007/s004150050057

25. Abou-Chebl A, Yadav JS, Reginelli JP, Bajzer C, Bhatt D, Krieger DW. Intracranial hemorrhage and hyperperfusion syndrome following carotid artery stenting: risk factors, prevention, and treatment. J Am Coll Cardiol. (2004) 43:1596-601. doi: 10.1016/j.jacc.2003.12.039

26. Moulakakis KG, Mylonas SN, Sfyroeras GS, Andrikopoulos V. Hyperperfusion syndrome after carotid revascularization. J Vasc Surg. (2009) 49:1060-8. doi: 10.1016/j.jvs.2008.11.026

27. Farooq MU, Goshgarian C, Min J, Gorelick PB. Pathophysiology and management of reperfusion injury and hyperperfusion syndrome after carotid endarterectomy and carotid artery stenting. Exp Transl Stroke Med. (2016) 8:7. doi: 10.1186/s13231-016-0021-2

28. van Mook WN, Rennenberg RJ, Schurink GW, Van Oostenbrugge RJ, Mess WH, Hofman PA, et al. Cerebral hyperperfusion syndrome. Lancet Neurol. (2005) 4:877-88. doi: 10.1016/S1474-4422(05)70251-9

29. World Medical Association. World Medical Association Declaration of Helsinki: ethical principles for medical research involving human subjects. JAMA. (2013) 310:2191-4. doi: 10.1001/jama.2013.281053

30. Galyfos G, Sianou A, Filis K. Cerebral hyperperfusion syndrome and intracranial hemorrhage after carotid endarterectomy or carotid stenting: a meta-analysis. J Neurol Sci. (2017) 381:74-82. doi: 10.1016/j.jns.2017.08.020

31. Sacco RL, Kasner SE, Broderick JP, Caplan LR, Connors JJ, Culebras A, et al. An updated definition of stroke for the 21st century: a statement for healthcare professionals from the American Heart Association/American Stroke Association. Stroke. (2013) 44:2064-89. doi: 10.1161/STR.0b013e318296aeca

32. Abreu P, Nogueira J, Rodrigues FB, Nascimento A, Carvalho M, Marreiros $\mathrm{A}$, et al. Intracerebral hemorrhage as a manifestation of cerebral hyperperfusion syndrome after carotid revascularization: systematic review and meta-analysis. Acta Neurochir (Wien). (2017) 159:2089-97. doi: 10.1007/s00701-017-3328-4

33. Timaran CH, Veith FJ, Rosero EB, Modrall JG, Valentine RJ, Clagett GP. Intracranial hemorrhage after carotid endarterectomy and carotid stenting in the United States in 2005 J Vasc Surg. (2009) 49:623-8; discussion 628-9. doi: 10.1016/j.jvs.2008.09.064

34. McDonald RJ, Cloft HJ, Kallmes DF. Intracranial hemorrhage is much more common after carotid stenting than after endarterectomy: evidence from the National Inpatient Sample. Stroke. (2011) 42:2782-7. doi: 10.1161/STROKEAHA.111.618769

35. Hussain MA, Alali AS, Mamdani M, Tu JV, Saposnik G, Salata K, et al. Risk of intracranial hemorrhage after carotid artery stenting vs. endarterectomy: a population-based study. J Neurosurg. (2018) 129:1522-9. doi: 10.3171/2017.8.JNS171142

36. Matsumoto S, Nakahara I, Higashi T, Iwamuro Y, Watanabe Y, Takahashi $\mathrm{K}$, et al. Near-infrared spectroscopy in carotid artery stenting predicts cerebral hyperperfusion syndrome. Neurology. (2009) 72:1512-8. doi: 10.1212/WNL.0b013e3181a2e846

37. Lee KJ, Kwak HS, Chung GH, Song JS, Hwang SB. Leptomeningeal collateral vessels are a major risk factor for intracranial hemorrhage after carotid stenting in patients with carotid atherosclerotic plaque. J Neurointerv Surg. (2016) 8:512-6. doi: 10.1136/neurintsurg-2014-011634

38. Zhang L, Dai D, Li Z, Duan G, Zhang YW, Yang P, et al. Risk factors for hyperperfusion-induced intracranial hemorrhage after carotid artery stenting in patients with symptomatic severe carotid stenosis evaluation. J Neurointerv Surg. (2019) 11:474-8. doi: 10.1136/neurintsurg-2018-013998

39. Huibers A, Calvet D, Kennedy F, Czuriga-Kovacs KR, Featherstone RL, Moll FL, et al. Mechanism of procedural stroke following carotid endarterectomy or carotid artery stenting within the International Carotid Stenting Study (ICSS) randomised trial. Eur J Vasc Endovasc Surg. (2015) 50:281-8. doi: 10.1016/j.ejvs.2015.05.017

40. McCabe DJ, Brown MM, Clifton A. Fatal cerebral reperfusion hemorrhage after carotid stenting. Stroke. (1999) 30:2483-6. doi: 10.1161/01.STR.30.11.2483

41. Abou-Chebl A, Reginelli J, Bajzer CT, Yadav JS. Intensive treatment of hypertension decreases the risk of hyperperfusion and intracerebral hemorrhage following carotid artery stenting. Catheter Cardiovasc Interv. (2007) 69:690-6. doi: 10.1002/ccd.20693 
42. Ogasawara K, Sakai N, Kuroiwa T, Hosoda K, Iihara K, Toyoda K, et al. Intracranial hemorrhage associated with cerebral hyperperfusion syndrome following carotid endarterectomy and carotid artery stenting: retrospective review of 4494 patients. J Neurosurg. (2007) 107:1130-6. doi: $10.3171 /$ JNS-07/12/1130

43. Cronenwett JL, Kraiss LW, Cambria RP. The society for vascular surgery vascular quality initiative. J Vasc Surg. (2012) 55:1529-37. doi: 10.1016/j.jvs.2012.03.016

44. Brott TG, Howard G, Roubin GS, Meschia JF, Mackey A, Brooks W, et al. Long-term results of stenting vs. endarterectomy for carotid-artery stenosis. N Engl J Med. (2016) 374:1021-31. doi: 10.1056/NEJMoa1505215
Conflict of Interest: The authors declare that the research was conducted in the absence of any commercial or financial relationships that could be construed as a potential conflict of interest.

Copyright $\odot 2020$ Zheng, Li, Liu, Guo, Zhao, Bai, Yan and Qu. This is an open-access article distributed under the terms of the Creative Commons Attribution License (CC $B Y)$. The use, distribution or reproduction in other forums is permitted, provided the original author(s) and the copyright owner(s) are credited and that the original publication in this journal is cited, in accordance with accepted academic practice. No use, distribution or reproduction is permitted which does not comply with these terms. 